\title{
Functional outcome of proximal femoral nailing for unstable intertrochanteric fracture in elderly
}

\author{
Ankit Jose*, Edward Nazareth, Vivian Roshan D'Almedia, \\ Mohan Kumar Challahalli Rudregowda
}

Department of Orthopaedics, Father Muller Medical College, Mangalore, Karnataka, India

Received: 04 July 2020

Revised: 11 August 2020

Accepted: 01 September 2020

\section{*Correspondence:}

Dr. Ankit Jose,

E-mail: ankitjose@gmail.com

Copyright: (c) the author(s), publisher and licensee Medip Academy. This is an open-access article distributed under the terms of the Creative Commons Attribution Non-Commercial License, which permits unrestricted non-commercial use, distribution, and reproduction in any medium, provided the original work is properly cited.

\section{ABSTRACT}

Background: This study is intended to analyse the functional outcome of proximal femoral nailing (PFN) for unstable intertrochanteric fractures in elderly.

Methods: The data was collected from the 35 patients with unstable intertrochanteric femur fracture who were subjected to PFN from 2015 to 2018. All patients were followed up at 3 months and 6 months after the operation to check the functional outcome based on harris hip score (HHS) and complication if any.

Result: In 35 patients, 1 patient was lost to follow-up and 34 patients were followed-up at 3 months and 6 months. All patient's union was achieved at 3 and 6 months follow up. The cause of fractures was trivial fall in all 35 patients. No incidence of non-union and delayed union was reported. Functional outcome was rated as per HHS, we got excellent results in 20 cases, good in 10, fair in 03 and poor in one patient at end of 6 months.

Conclusions: PFN provides stable fixation and early post-operative mobilization with fracture union especially complex proximal femoral fractures which includes unstable, communited, reverse oblique fractures and fractures in osteoporotic bones. PFN has shown excellent results in our study.

Keywords: Proximal femur nailing, Intertrochanteric fractures, Harris hip score

\section{INTRODUCTION}

Trochanteric fractures are one of the most common injuries sustained predominantly in patients over sixty years of age. They are three to four times more common in osteoporotic patients; trivial fall being the most common mechanism of injury. ${ }^{1}$ For many, this fracture is often a terminal event resulting in death due to cardiac, pulmonary or renal complications. Approximately 10 to $30 \%$ of patients die within one year of an intertrochanteric fracture..$^{2}$ Little attention was paid to these fractures in the past, as they occur through the cancellous bone with excellent blood supply and they healed without any active treatment. However conservative treatment usually resulted in malunion with varus and external rotation deformity resulting in a short limb gait and a high rate of mortality due to complications of recumbency and immobilization. The goal of treatment of an intertrochanteric fracture is the restoration of the patient to his or her pre-injury status as early as possible. This led to internal fixation of these fractures to increase patient comfort, facilitate nursing care, decrease hospitalization and reduce complications of prolonged recumbency. ${ }^{3}$ The type of implant used has an important influence on complications of fixation. Sliding devices like the dynamic hip screw have been extensively used for fixation. However, if the patient bears weight early, especially in comminuted fractures, these devices can penetrate the head or neck, bend, break or separate from the shaft. Intramedullary devices like the proximal femoral nail (PFN) have been reported to have an advantage in such fractures as their placement allowed the implant to lie 
closer to the mechanical axis of the extremity, thereby decrease the lever arm and bending moment on the implant. ${ }^{4}$ They can also be inserted faster, with less operative blood loss and allow early weight bearing with less resultant shortening on long term follow up. In view of this observation the present study is undertaken to assess the functional outcome of proximal femur fractures managed by proximal femoral nailing.

\section{METHODS}

The patients admitted to the department of orthopedics at Father Muller Medical College and Hospital, Mangalore with unstable intertrochanteric fracture of femur from August 2015 to August 2017 were selected. A sample size of 35 patients operated during the period was considered. The data was collected from the patients in a specially designed case record form (CRF) by taking history of illness, clinical examination and relevant investigations. Finally, after the diagnosis the patients are selected for the study depending on the inclusion and exclusion criteria. Post operatively all the cases are followed for the minimum period of 6 months.

\section{Inclusion criteria}

Inclusion criteria for selection of subject was equal to or more than 65 years.

\section{Exclusion criteria}

Exclusion criteria for selection of subject were stable fractures, open fractures, polytrauma, other fractures in ipsilateral or contralateral limb, earlier operated for other problems in same or opposite limb criteria to assess results

The functional outcome of patients is evaluated by HHS. ${ }^{5}$ A total score below 70 points is considered a poor result, 70 to 80 fair 80 to 90 good 90 to 100 excellent. ${ }^{6}$ Pre injury walking ability was recorded for all patients. ${ }^{7}$

\section{Investigations required for the study}

Investigation required for the study were Routine preoperative blood investigations, X-Ray Pelvis with both hips- AP view, X-Ray of fractured hip- lateral view, radiological examination will be repeated post-operatively and at the end of 6 weeks, 12 weeks and 6 months intervals. Patients will be followed up at 3 months and 6 months.

\section{Implant details PFN}

PFN offers several potential advantages over the sliding hip screw and plate 6 like a Proximal femoral nail provides more efficient load transfer than does a sliding hip screw, because of its location, a shorter lever arm of the proximal femoral nail can decrease tensile strain on the implant so decreasing the risk of implant failure, because a proximal femoral nail incorporates a sliding hip screw, the advantage of controlled fracture impaction is maintained, the proximal femoral nail location limits the amount of sliding and therefore limb shortening and deformity that can occur, insertion of proximal femoral nail requires shorter operative time and less soft tissue dissection than a sliding hip screw, so decreasing the overall morbidity. Determination of nail diameter nail diameter was determined by measuring diameter of the femur at the level of isthmus on an AP X-ray, determination of neck - shaft angle neck shaft angle was measured in unaffected side in AP X-ray using goniometer, length of the nail a standard length PFN ( $250 \mathrm{~mm}$ ) was used in all our cases 26 surgical technique. All patients were positioned supine on a fracture table. The unaffected lower limb was flexed and abducted to allow easy access for the image intensifier. Reduction: The fracture was reduced by traction in neutral, slight internal or external rotation depending on the nature of the fracture and checked by anteroposterior and lateral views on the image intensifier. All fractures were reduced by the closed method. The objective of reduction is to confer weight bearing stability and correct varus and rotational deformities. In stable fractures this is achieved by reduction of the calcarfemorale. Method of fixation: a lateral skin incision is made extending from the hip of the trochanter proximally for $3-8 \mathrm{~cm}$ depending on the size or obesity of the patient. The gluteus maximusaponeurosis is split in line with its fibers from the hip of the trochanter proximally for $5 \mathrm{~cm}$ and then the gluteus medius is split in line with its fibers. An entry point is made just medial to the tip of the greater trochanter with a curved awl. a 3.2 $\mathrm{mm}$ tip threaded guide pin is inserted through the tissue protection guide pin centering sleeve beyond the fracture site. The position of the pin is checked on image intensifier. The proximal femoral reamer was then used to prepare the proximal portion of the femur. In this study a 9- or 10-mm nail was used depending on the diameter of the femoral canal with a fixed length of $250 \mathrm{~mm}$. The mediolateral angle of the nail allows easy insertion. The proximal femoral nail was then attached to the jig and passed over the guide wire into the proximal femur and across the fracture site into the femoral shaft. Once the proximal femoral nail is inserted, the head and neck of femur are reamed for the cannulated hip screw, which is $8 \mathrm{~mm}$ in diameter and varying from 70 to $110 \mathrm{~mm}$ in length. Under radiographic guidance the hip screw is inserted into the lower half of the neck of femur within 5-10 mm from the subchondral bone of the femoral head. The stabilization screw which is $6.4 \mathrm{~mm}$ in diameter cannulated and varying from $60-100 \mathrm{~mm}$ in length was then inserted into the proximal slot of the nail under radiographic guidance after the drilling for the same. Then incisions were made and distal locking bolts were inserted using the jig from the lateral cortex of femur through the slot in the nail. All the incisions were closed and sterile dressings applied. Postoperative care: All patients were given perioperative antibiotics for 24 to 48 hours and deep venous thrombosis prophylaxis. Patients were allowed to sit up in bed on the second post-operative day. Static quadriceps exercise where started on the second and third post-operative day. Sutures were removed after 10 to 14 
days. Patients were mobilized non-weight bearing as soon as the pain or general condition permitted. Weight bearing was commenced depending upon the stability of the fracture and adequacy of fixation, delaying it for patients with unstable or inadequate fixation. All the patients were followed up at monthly intervals for a period of 6 months and check X-rays were taken to assess fracture union and signs of failure of fixation. The functional outcome was assessed based on the HHS hip score as follows: Clinical assessment: All patients were clinically assessed by using the HHS. Radiological assessment: All patients were radiologically assessed for progression and time of union, fracture alignment, implant related complications.

\section{HHS}

Pain (check one) none or ignores it (44) slight, occasional, no compromise in activities (40) mild pain, no effect on average activities, rarely moderate pain; may take aspirin (30) moderate pain, tolerable but makes concession to pain. some limitation of ordinary activity or work. may require occasional pain medication stronger than aspirin (20) marked pain, serious limitation of activities (10) totally disabled, crippled, pain in bed, bedridden (0) limp none (11) moderate (5) severe (0) support none (11) cane for long walks (7) cane most of time (5) one crutch (3)two canes (2) two crutches or not able to walk (0) distance walked unlimited (11) six blocks (8) two or three blocks (5) indoors only (2) bed and chair only (0) sitting comfortably in ordinary chair for one hour (5) on a high chair for 30 minutes (30) unable to sit comfortably in any chair (0) enter public transportation yes (1) no (0) stairs normally without using a railing (4) normally using a railing (2) in any manner unable to do stairs (0) put on shoes and socks with ease (4) with difficulty (2) unable (0) absence of deformity (all yes $=4$; less than $4=0$ ) less than $30^{\circ}$ fixed flexion contracture (yes, no) less than $10^{\circ}$ fixed abduction (yes, no) less than $10^{\circ}$ fixed internal rotation in extension (yes, no) limb length discrepancy less than 3.2 $\mathrm{cm}$ (yes, no) range of motion (*indicates normal) flexion $\left(* 140^{\circ}\right)$ abduction $\left(* 40^{\circ}\right)$ adduction $\left(* 40^{\circ}\right) 31$ external rotation $\left(* 40^{\circ}\right)$ internal rotation $(* 40)$ range of motion scale $211^{\circ}-300^{\circ}(5) 61^{\circ}-100$ (2) $161^{\circ}-210^{\circ}$ (4) $31^{\circ}-60^{\circ}(1)$ $101^{\circ}-160^{\circ}(3) 0^{\circ}-30^{\circ}(0)$ range of motion score- $t=$ total hhs- grading of harris hip score $<70$ points- poor, $70-79$ points- fair $80-89$ points- good $90-100$ points- excellent. ${ }^{6}$

\section{RESULTS}

This study was a prospective, time bound, hospital-based study conducted in Father Mullers Medical College Hospital. The study included 35 patients with unstable intertrochanteric fracture of femur that were treated with PFN. The analysis of the patient data, intra operative data $\&$ post-operative outcome was as follows.

The age distribution was from 63 years to 91 years. The majority of patients were from 71 to 80 years. The average age was 77.09 (Table 1).
Table 1: Age distribution of patients.

\begin{tabular}{|lll|}
\hline $\begin{array}{l}\text { Age group (in } \\
\text { years) }\end{array}$ & Frequency & Percentage \\
\hline $\mathbf{7 0}$ and below & 6 & 17.1 \\
\hline $\mathbf{7 1 - 8 0}$ & 18 & 51.4 \\
\hline Above 80 & 11 & 31.4 \\
\hline Total & 35 & 100.0 \\
\hline
\end{tabular}

The Sex distribution shows the majority of patients were female, $74.3 \%$ (Table 2).

Table 2: Sex distribution.

\begin{tabular}{|lll|}
\hline Sex & Frequency & Percentage \\
\hline Female & 26 & 74.3 \\
\hline Male & 9 & 25.7 \\
\hline Total & 35 & 100.0 \\
\hline
\end{tabular}

The mode of injury in our series was trivial fall in all 35 patients (Table 3).

Table 3: Mode of injury.

\begin{tabular}{|lll|}
\hline Mode of injury & Frequency & Percentage \\
\hline TF & 35 & 100.0 \\
\hline
\end{tabular}

Here, 33 patients had type 3 fracture $(5.7 \%)$ and 2 patients had type 2 fracture $(94.3 \%)$ (Table 4$)$.

Table 4: Type of fracture.

\begin{tabular}{|lll|}
\hline $\begin{array}{l}\text { Evans classification } \\
\text { for intertrochanteric } \\
\text { fracture (IT) }\end{array}$ & Frequency & Percentage \\
\hline Unstable fracture & 35 & 100.0 \\
\hline
\end{tabular}

The pre-injury walking ability of the patients was classified as per grades described by sahlstrand (Table 5 and 6).

Table 5: Classification of pre-injury walking ability.

\begin{tabular}{|ll|}
\hline Grade & Pre-injury walking ability \\
\hline Grade 1 & walk without support \\
\hline Grade 2 & walk with a cane or minimal support \\
\hline Grade 3 & $\begin{array}{l}\text { walk with 2 canes, crutches or living } \\
\text { support }\end{array}$ \\
\hline Grade 4 & confined to bed or wheel chair \\
\hline
\end{tabular}

Table 6: Pe-injury walking ability.

\begin{tabular}{|lll|}
\hline Grade & Frequency & Percentage \\
\hline Grade 1 & 35 & 100.0 \\
\hline
\end{tabular}




\section{Operative complications}

\section{Immediate complications}

We had no incidence wound infections.

\section{Delayed complications}

Two cases showed varus $<10$ degree. two cases had shortening up to $1 \mathrm{~cm}$ who were treated with sole raise, we had no cases of nonunion, three patients had knee stiffness. Patients improved after rigorous physiotherapy.

\section{Duration of hospitalization}

The average duration of hospital stay was 20 days (ranging from 15 to 30 days). Follow up all patients were followed up at 3 and 6 months respectively. Patients were followed up, for a maximum period of 6 months.

\section{Radiological union}

Radiological union was said to be achieved, on the evidence of obliteration of fracture lines and trabecular continuity between the two fragments on anterioposterior and lateral X-rays in three cortices.

The average time of union was 14.2 weeks, Maximum number of fractures united between 12 to 18 weeks (Figure 1).
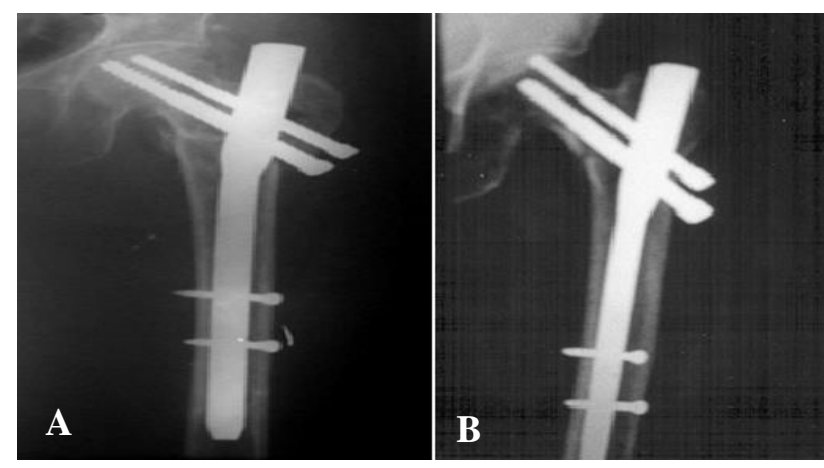

Figure 1: (A) Immediate post-operative (B) 6-months post-operative

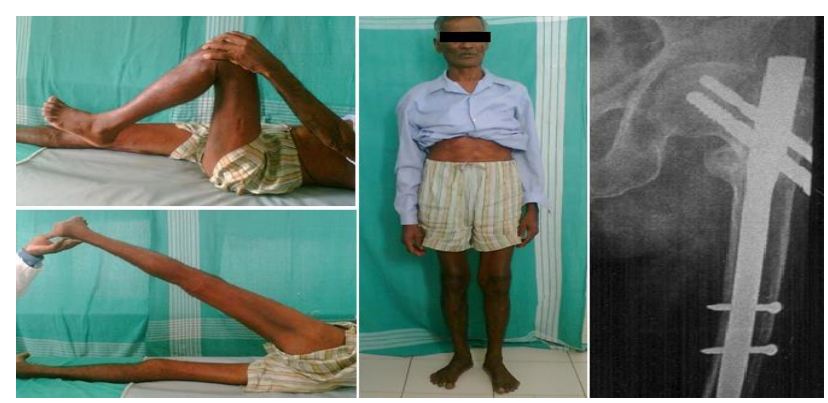

Figure 2: 3-6 months post op clinical photos and X-rays.
At the end of 3-month HHS was poor for 4 patients $11.8 \%$, fair for 1 patient $2.9 \%$, good for 25 patient $73.5 \%$ and excellent for 4 patient $11.8 \%$. Mean HHS at the end of 3 month was 80.134. We lost follow up of 1 patient in 35 patients that are taken in account.

Table 7: Functional outcome at end of 3 months.

\begin{tabular}{|lll|}
\hline Functional outcome & Frequency & Percentage \\
\hline Poor & 4 & 11.8 \\
\hline Fair & 1 & 2.9 \\
\hline Good & 25 & 73.5 \\
\hline Excellent & 4 & 11.8 \\
\hline Total & 34 & 100.0 \\
\hline
\end{tabular}

Functional outcome at the end of 6 months was poor for 1 patient $2.9 \%$, fair for 3 patients $8.8 \%$, good for 10 patients $29.4 \%$, excellent for 20 patients $58.8 \%$. Mean HHS at the end of 6 month was 88 (Figure 2).

Table 8: Functional outcome at end of 6 months.

\begin{tabular}{|lll|}
\hline Functional outcome & Frequency & Percentage \\
\hline Poor & 1 & 2.9 \\
\hline Fair & 3 & 8.8 \\
\hline Good & 10 & 29.4 \\
\hline Excellent & 20 & 58.8 \\
\hline Total & 34 & 100.0 \\
\hline
\end{tabular}

\section{DISCUSSION}

Restoring stability by early fixation and early mobilization are the keys steps in reducing mortality and morbidity in intertrochanteric fracture of femur. To achieve a stable fixation various implants have been used in which DHS was most time tested and frequently used and secondly proximal femoral nail which was minimal invasive intramedullary device. In our current study 35 patients with intertrochanteric fracture of femur were studied and results compared with others studies.

\section{Age and sex distribution}

The average age for trochanteric fractures is reported to be 66-76 years. In our series, the highest number of patients was in the 71-80 years age group and average age was 77.09. All the fractures that occurred in patients above 63 years were due to trivial fall. Fractures were seen more common in females which accounted for $74.3 \%$. This supports the view that bone stock plays an important role in the causation of fractures in the elderly, which occur after a trivial fall. ${ }^{1}$ no attempt was made to measure the degree of osteoporosis by the singh index, as it involves a great inter-observer variability and depends on good quality X-rays. In addition, the accuracy of the singh index has been questioned by authors such as Koot et al. ${ }^{4}$ 


\section{Mode of injury}

Causes of extracapsular femur fracture was fall from height, road traffic accident and most common being trivial fall. In our 35 patients $(100 \%)$ had history of trivial fall. Trivial fall was seen elderly aged above 60 years. Post-menopausal women and elderly patients are affected by osteoporosis this weakens the bone matrix leading low velocity injury.

In a study conducted by wei ting lee et al case series showed younger patients (mean age, 38.7 years) were more commonly involved in high-energy trauma such as motor vehicular accidents $(n=10)$, falls from a height $(n=2)$, crush injuries $(n=3)$, and others $(n=1)$; older patients (mean age, 67.7 years) were more commonly involved in low-energy trauma such as falls during walking $(\mathrm{n}=10){ }^{8}$

\section{Type of fractures}

Our series consisted of 35 intertrochanteric fractures as classified according boyd and griffins classifications. 33 patients had type 3 fracture $(5.7 \%)$ and 2 patients had type 2 fracture (94.3\%). All 35 patients underwent PFN. Reason for high type 3 inter trochanteric fractures are reduced bone stock in elderly and postmenopausal women.

\section{Pre-injury walking ability}

All patients in our study had a pre inury waking ability of grade 1 -walking without support prior to the injury.

\section{Functional outcome}

The functional outcome in our study was based on harris hip score. Out of 35 patients one patient was lost to follow up. At the end of 3-month HHS was poor for 4 patients $11.8 \%$, fair for 1 patient $2.9 \%$, good for 25 patient $73.5 \%$ and excellent for 4 patient $11.8 \%$. Mean HHS at the end of 3 month was 80.134 , was good according to my study. Functional outcome at the end of 6 months was poor for 1 patient $2.9 \%$, fair for 3 patients $8.8 \%$, good for 10 patients $29.4 \%$, excellent for 20 patients $58.8 \%$. Mean HHS at the end of 6 month was 88 , was good according to our study.

In a study by uzen et al which included 35 patients, the mean HHS was 82.1 at the end of 32.4 months. The result was excellent in 11 patients $31.4 \%$, good in 15 patients $42.9 \%$, fair in 7 patients $20 \%$, and poor in two patients $5.7 \%{ }^{9}$

\section{Limitations of our study}

This was a descriptive study, due to the absence of a control or comparator group, it is difficult make a definitive conclusion whether this implant was the best treatment option for all intertrochnateric fractures of femur. To make a definitive conclusion, a randomised controlled trial would be needed, our sample size reflects the routine patient inflow in our hospital. A study with a larger sample size would have made a better assessment of this surgical intervention, our study was time bound, the patients were followed up for a minimum of 3 months and a maximum of 6 months. Therefore, the long-term effects of this intervention remain unknown in our cohort. A longer follow up would have made a complete assessment of this surgical intervention.

\section{CONCLUSION}

We conclude that in unstable intertrochanteric fractures, PFN has significantly better outcomes in terms of earlier restoration of walking ability. In addition, as the PFN requires shorter operative time and a smaller incision. PFN provides stable fixation and early post-operative mobilization with good fracture healing especially unstable intertrochanteric femoral fractures in osteoporotic bones. Even though not free of complication but has showed good to excellent results in our study based on functional outcome and early return to pre injury walking ability thus reducing mortality and morbidity rates in elderly patients.

Funding: No funding sources

Conflict of interest: None declared

Ethical approval: The study was approved by the institutional ethics committee

\section{REFERENCES}

1. Kaufer H. Mechanics of the Treatment of Hip Injuries. Clin Orthop. 1980;146:53-61.

2. Kyle RF, Gustilo RB, Premer RF. Analysis of six hundred and twenty-two intertrochanteric hip fractures. A retrospective and prospective study. J Bone Joint Surg. 1979;61A:216-21.

3. Kaufer H, Mathews LS, Sonstegard D. Stable Fixation of Intertrochanteric Fractures. J Bone Joint Surg. 1974;56A:899-907.

4. Koot VCM, Kesselaer SMMJ, Clevers GJ, Hooge P, Weits TW. Evaluation of Singh Index for Measuring Osteoporosis. J Bone Joint Surg. 1996;78B:831-4.

5. Harris WH. Traumatic arthritis of the hip after dislocation and acetabular fractures: treatment by mold arthroplasty. An end-result study using a new method of result evaluation. J Bone Joint Surg Am. 1969;51(4):737-55.

6. Marchetti P, Binazzi R, Vaccari V, Girolami M, Morici F, Impallomeni C, Commessatti M, Silvello L. Long-term results with cementless Fitek (or Fitmore) cups. J Arthroplasty. 2005;20(6):730-7.

7. Sahlst rand T. The Richards Compression and Sliding Hip Screw System in the Treatment of Intertrochanteric Fractures. Acta Orthop Scand. 1974;5:213-9.

8. Wei Ting Lee, Diarmuid Murphy, Fareed HY Kagda, Joseph Thambiah. Proximal femoral locking compression plate for proximal femoral fractures. J Orthopaed Surg. 2014;22(3):287-93. 
9. Uzun M, Erturer E, Ozturk I, Akman S, Seckin F, Ozcelik IB. Long term radiographic complications following treatment of unstable intertrochanteric femoral fractures with the proximal femoral nail and effects on functional results. Acta Orthop Traumatol Turc. 2009;43:457-63.
Cite this article as: Jose A, Nazareth E, D'Almedia VR, Rudregowda MKC. Functional outcome of proximal femoral nailing for unstable intertrochanteric fracture in elderly. Int J Res Orthop 2020;6:1186-91. 